\title{
Managing Small Language Programs in Changing Times
}

\section{Marc L. Greenberg}

Marc L. Greenberg is professor of Slavic linguistics and director of the School of Languages and Literatures at the University of Kansas.
THE following discussion excerpts part of a plenary discussion, Small Programs in Varied Contexts: A Roundtable, that took place during the 2016 ADFL Summer Seminar West on 3 June at the Middlebury Institute of International Studies at Monterey. I moderated the roundtable, which sought perspectives from leaders of programs from a variety of institutions, public and private, including a community college, liberal arts colleges, and research universities distributed throughout the United States. The panelists included Carol Reitan, a French specialist and former chair of the Department of World Languages and Cultures at the City College of San Francisco; Sahie Kang, professor of Korean and director of the School of Korean at Middlebury College; Mahmoud Abdalla, professor of Arabic and director of the Arabic Language School at Middlebury College; Omar Ka, a specialist in French, Wolof, and African linguistics at the University of Maryland Baltimore County and a member of the ADFL Executive Committee; Zsuzsanna Abrams, a specialist in German and applied linguistics and former department chair at the University of California, Santa Cruz; and Colleen Ryan, professor of Italian at Indiana University, Bloomington. The context of the discussion is what might have been referred to in another period as a crisis in higher education but what instead has become the new normal: shrinking budgets; pressure to raise efficiency and provide accountability metrics; competition for students anxious about rising tuition, debt, and postgraduate employment; and increased competition to gain student-credit-hour production and majors to generate tuition revenue. All this presents itself on the background of the dissonance between the growing real-world need for language and intercultural competence, on the one hand, and student ambivalence to foreign language study, on the other. The discussion below proceeds from the questions I posed to the panel: "What has worked for you in your program? What creative strategies might you recommend to other chairs or faculty members managing small programs?”

\section{Carol Reitan, City College of San Francisco}

The City College of San Francisco (CCSF) Foreign Languages Department is shrinking. Once a mighty force with 3,120 students enrolled in courses across our nine languages (in two semesters of 2011), we lost over half our students and had only 1,450 students in spring and fall 2016. Many things conspired to create this situation; some cite changes in state repeatability rules for California community colleges, some cite changes in San Francisco's demographics. But the biggest reason for this dramatic drop in students was our accreditation situation.

Although no academic programs were criticized, CCSF almost lost its accreditation because of issues surrounding our administration, the number of deans (not enough, we were told), and other things not connected to the classroom. To stay alive

(c) 2018 Marc L. Greenberg

CrossRef DOI 10.1632/adfl.44.2.30 
Managing Small

Language Programs in

Changing Times

Marc L. Greenberg as a department and to keep all our languages and our programs intact through the parade of new administrators and their changing policies (we're on our fourth chancellor in as many years), we worked on both in-reach and outreach. Because we are a community college, about half our students come from the community. We needed to let folks know we were still there. We handed out flyers to the public in subway and streetcar stations, libraries, cafés, and restaurants. Our instructors reached out to their language communities and developed new courses and partnerships. One of the most successful collaborations has been with the San Francisco Unified School District, whose students graduating from Chinese immersion $\mathrm{K}-8$ schools come to us to study Mandarin at levels higher than are available at their high schools. We tried offering new class meeting times, an online lab component in Moodle, and student club activities. In-reach included getting our faculty members to be active on the curriculum committee, academic senate, American Federation of Teachers, and in other committees to be visible on campus and make our successes and challenges known. Although we kept shrinking, we were able to keep our degrees and certificates intact.

This worked for the first three years of this crisis. Now, enrollments are up. Students are coming back. But, unfortunately, our current administration has decided to try a new scheduling protocol, in the light of the overall poor enrollments of the past three years. To combat this, we are looking forward to trying many of the strategies that worked at other schools represented on this panel. Our new course, Introduction to Intercultural Communication and Language Learning, will soon go before the curriculum committee.

\section{Sahie Kang, Middlebury College}

One of the challenges in managing a small language program is finding and securing resources. There are still many funders available in the target-language country and local language communities, though. At Middlebury, for example, the Korea Foundation supported the School of Korean by funding generous financial aid packages for students. Once funding is approved, it is important to communicate with the funder and include them in any school events and activities. Also, networking with the target-language country's consul and businesspeople is important. They can also support our program by providing free lectures on culture and society and cultural events. Visiting our campus, the Korean consul general in San Francisco and Korean culture center in Los Angeles offered an authentic martial-arts performance, free lectures on traditional Korean culture, and teaching materials. Local Korean food companies also sponsored a school event.

Often small language programs lack teaching staff. On some campuses, Fulbright scholars are available for language tutoring. There are various distance-learning resources and videoconference systems available for connecting with native-speaking students in the target-language country. The Middlebury School of Korean received a free, semester-long "e-school" course, a live, interactive lecture by a Korean professor in a Korean university through Polycom. In addition, online interaction with native-speaking students in Korea would be a good option for us next year.

Student enrollment is also a continuing challenge for small language programs. For student recruitment, working closely with staff members in the marketing and 
Managing Small

Language Programs in

Changing Times

Marc L. Greenberg recruiting offices, academic advising office, student financial aid office, international student office, and dean's office is key, and it is important to inform them of changes at the school: updated information, new programs, new funding, and any events and activities. When these staff members talk to potential students, they are always willing to share program information with them. Moreover, networking with former students for sharing program updates and community news using social networks is helpful to maintain their interest in the language program and turn them into future advocates and supporters of it. Likewise, it is helpful to take advantage of any school events, such as an Asian culture festival, homecoming, and so forth, in which our language program can be promoted. We must help students understand that learning foreign languages will help them become global citizens who are equipped to resolve the ever-more-complex world issues and conflicts they will face.

\section{Mahmoud Abdalla, Middlebury College}

The success of small programs depends mainly on the availability of resources and the recruiting of dedicated and committed students and faculty members. The demand for learning Arabic as a foreign or second language has increased dramatically after the tragic events of 9/11, and as a result Arabic became one of the top ten taught languages in the United States after being considered a less commonly taught language for decades (Goldberg et al.). Enrollments in the Middlebury Arabic School have gone from around eighty students in the late 1990s to two hundred students in 2016, including the addition of the graduate programs in Arabic studies and teaching Arabic as a foreign language. Because of this unexpected change and to meet the increasing demand for Arabic, many teachers who lack experience in teaching foreign languages were hired, which in turn worsened overall program outcomes. To overcome this problem, the Middlebury Arabic School has established a strong network with universities and academic institutions in the Middle East, Europe, and the United States, through which it has successfully hired about twenty excellent teachers who bring Arab culture to the students at Middlebury at the Mills campus. These teachers work alongside Middlebury Arabic school senior faculty members, who have considerable experience in immersive language teaching.

The school has now become a major center for training professional Arabic teachers. This was done by conducting teacher training workshops, providing in-service training, and organizing international conferences and seminars independently and in collaboration with other prominent institutions in the Middle East, such as Al Akhawayn University in Morocco. Our teachers come from eleven Arabic-speaking countries, but we are still unable to hire teachers from the Arabian (Persian) Gulf States on a regular basis, in great part because of the financial constraints and the differences between the work environments and the cultural and social obligations in the United States and the Gulf region. However, several teachers from other nationalities who work at Emirates, Saudi, and Omani universities have been hired to fill in the gap and provide opportunities for our students to learn more about various aspects of Arab culture and contemporary Gulf society.

Another challenge is that many of the universities and colleges in the United States use the Al-Kitaab series from Georgetown University Press and usually require their 
Managing Small

Language Programs in

Changing Times

Marc L. Greenberg students to use this textbook to join higher-level classes upon their return from the summer programs. The dominance of the Al-Kitaab series and the linkage between the students' proficiency level and the number of lessons drawn from this textbook adds pressure to small Arabic summer and immersion programs and seriously affects the quality of learning and teaching. To address these pedagogical issues, the school designed its own curriculum that aims at raising the students' proficiency level using authentic materials that are relevant to their interest and area of study. This effort is supported by the unique cocurricular program that promotes the students' learning curiosity and reinforces what they learn during the summer session. In addition, four to six dialect classes are offered every summer to prepare students for the studyabroad experience and to help them communicate with educated native speakers.

The school has developed a four-hour written entrance exam, followed by an oral interview, to help us assess students' language abilities, accommodate their learning needs, and place students in the appropriate level before they join the summer session. Although we use a well-developed placement examination, we realize that the gap between the language abilities of the students who are enrolled in the same level is always wider than the gap we usually find in regular year Arabic programs. The differences in the students' language abilities may be attributed to the diversity of the learners and the kind of language training they receive. To narrow this gap and help the students reach the same proficiency level by the end of the summer session, we provide extensive training for our faculty members on how to deal with individual differences and encourage them to use effective teaching strategies. We also offer additional review classes and one-on-one intensive sessions, which are conducted by graduate interns.

Enrollment in Arabic classes is now lower, in part because of the instability in the Middle East. Despite the competition and the recent low enrollment, the Middlebury Arabic School meets its projected enrollment every summer. The successful marketing plan, the administrative support from the Middlebury Language Schools, and the quick and regular response to the applicants' questions and inquiries are some reasons for this success.

\section{Omar Ka, University of Maryland Baltimore County}

We seek small grants for program improvement from places such as the Korea Foundation or Japan Foundation. Such grants would pay, for instance, for launching or developing the language program. We recruit dynamic instructors who are willing to do more than just teach; they need to be involved in recruitment, advertising, and advising efforts to get the program on the map. We encourage collaboration with larger, more established programs such as Spanish or French. We have monthly meetings of a teaching circle where language instructors can exchange ideas on pedagogical issues that run across languages (this also helps reduce possible feelings of isolation). We develop ways in which students in small programs can meet and mingle outside the classroom (e.g., dinner parties featuring food from the relevant culture, field trips). We make sure to connect with other programs or area studies on campus, such as global studies, Asian studies, and Africana studies. Instructors may seek affiliate faculty status in those programs. 
Managing Small

Language Programs in

Changing Times

Marc L. Greenberg
With regard to creative strategies for sustaining small programs, we suggest the following. If the small program is in a language department, chairs may think about ways to fully integrate the program into the department-for example, by creating a single degree with various language options. In our case, we have a BA in modern languages, linguistics, and intercultural communication, with options such as French, Spanish, Russian, Arabic, Chinese, linguistics, and so forth. Chairs may also want to keep close communication with their dean (and possibly provost) to make sure they understand the importance of the small program and the need to develop it in the light of changes in today's world. During the orientation for first-year and transfer students, make sure that advisers are informed of the range of languages offered by the campus (not just the traditional languages). Extend recruitment efforts to nearby high schools; keep in touch with high school language teachers and school administrators. Develop collaboration with nearby community colleges regarding transfer of language credits. Develop collaboration with nearby similar institutions. We at UMBC are a member of a cooperative of academic programs in Maryland that includes Johns Hopkins University, Towson University, Goucher College, and Loyola College. This cooperative has allowed us to organize meetings devoted to less commonly taught languages.

\section{Zsuzsanna Abrams, University of California, Santa Cruz}

The German program in the Department of Languages and Applied Linguistics at the University of California, Santa Cruz (UCSC), has two full-time faculty members (one lecturer and one research professor). As needed, temporary lecturers are hired to cover sabbatical or other leaves. In addition to German, the department houses ten languages; Spanish, French, and Japanese are the biggest caucuses, both in the number of students and number of faculty. One major in Spanish studies is hosted in the department (with approximately sixty majors each year), and a second major in multilingualism and applied linguistics. Students studying German can major in global economics (hosted by the Department of Economics), linguistics or language studies (both in the Department of Linguistics), literature (in Literature) or German studies (in History). Most learners in the first- and second-year curriculum, however, take German out of personal interest and hail from natural sciences, engineering (including computer sciences), or the arts. While it is wonderful to teach highly motivated students who are not learning German just because it is a requirement, curricular planning can be difficult because these students discontinue their language studies as they progress in their majors and qualify for required upper-division courses in their own departments. Three interrelated details about our program arise from this context. First, German-language courses are primarily in the service of other departments. Second, enrollments are difficult to predict, and small language programs are not as flexible as bigger ones in being able to cancel or add courses. Third, the considerable administrative burden falls on the small number of faculty members to meet departmental, divisional, and campus requirements, so ensuring morale is essential. Sustaining a small program in this situation is a challenging endeavor and requires creative solutions by the faculty and campus administrators. 
Managing Small

Language Programs in

Changing Times

Marc L. Greenberg
As the report of the MLA Ad Hoc Committee on Foreign Languages states, language departments are still often two-tiered systems, with upper-division content courses constituting almost a completely separate curriculum from lower-division languages courses. When your language program has only lower-division courses and content courses, unrelated to the language for the most part, are in other departments, you have to ensure excellent communication among the diverse units and yourself. If a department changes its major requirements, your program needs to know about it so that you can schedule more courses at appropriate levels or reduce them, if necessary. Biannual meetings with faculty (e.g., undergraduate advisers) from other departments can facilitate the mutual flow of information and collaborative planning. At the same time, knowing about awards or important placements of students who are majoring in other departments but received an award related to the target language can help your department advocate for continuing your language, in spite of low(er) overall numbers. For example, last year a student majoring in cellular and molecular biology was accepted into a master's program in Munich, Germany, because she had studied German with us and met the language requirements for the program. Another student, a history major, spent a year in Germany on the Fulbright program because of having taken our language courses. In addition, examining the number of students who study abroad as a result of having participated in a language program can be useful data, since most colleges and universities in the United States recognize the need to help train global-ready graduates. Such details can help convince administrators that enrollment numbers only tell part of the story and that diverse language offerings help create a symbiotic relationship with the broader campus community.

The second point, regarding enrollment, is a constant struggle for our language program. Because the German language program is so small, courses are fairly rigidly set, disallowing the flexibility in scheduling that might help boost enrollments. We have German 1 (first quarter) only in the fall, German 2 (second quarter) only in the winter, and German 3 (third quarter) only in the spring. The same sequence is reflected in the second-year program: German 4 in the fall, German 5 in the winter, and German 6 in the spring. Under this arrangement, students who do not find out about German language courses until their second or third quarter have to wait a full year before enrolling, at which point they are also able to register for courses pertaining to their major and quit language studies after two or three quarters, significantly reducing the number of enrollments in the second-year program. Advertising during first-year orientation, as well as reserving some spots on the roster for incoming freshmen and transfer students, seems to help boost enrollments in a population that is more likely to stay with the program for the entire two years. The same fiscal and programmatic inflexibility also makes it impossible for us to add a section when a large number of students are on the waiting list or to cancel a section when a course is underenrolled. There is neither a budget for expansion nor are there faculty members available on short notice (or for a short term). As a result, we have sometimes had German 1 and German 4 classes with more than thirty students in each section.

The third challenge in small(er) language programs is establishing and maintaining faculty morale. Faculty members and chairs can help support a small program 
Managing Small

Language Programs in

Changing Times

Marc L. Greenberg in several ways. First and foremost, the faculty members who will be running the program must be dedicated to it. One dynamic person can help a program thrive, but one uncommitted person can make it difficult to maintain. Hosting a movie series related to the language can both advertise the program more broadly and get students excited about the language they are studying. Weekly language tables and field trips can also attract learners and make the program appealing, but they take time and effort for the instructor to organize (and relevant destinations must be available). Chairs can help support small-program faculty members by allocating funding to purchase or rent movies, for example, or to support the language in other ways (e.g., host a monthly tea, order books for student awards). Second, all efforts must be made to help open communication among faculty members working in a small caucus. Close collaboration is essential to create a coherent, cohesive program and keep faculty morale high. The issues of open communication, effective problem solving, and close collaboration should be addressed explicitly to ensure that all faculty members contribute to the program evenly, in a positive, collegial environment.

Finally, a small number of faculty members in smaller language programs have to take on sizable administrative responsibilities, designing the curriculum, conducting placement exams and other assessments for scholarship or Fulbright purposes, responding to student queries about the curriculum, performing outreach duties, staying in touch with other faculty members across campus whose programs link to the language, and establishing program learning objectives for which they also have to collect student data (which are not only required but can also help promote the program to campus administrators). There is often no opportunity to rotate these responsibilities to reduce service obligations, as larger programs can arrange to do. Especially in the case of new, junior faculty members, providing effective modelsand staff support-is essential. The faculty itself can be proactive by keeping meticulous records so that materials do not need to be regenerated each year. The chair or staff members should also keep copies of such materials, because faculty turnover may be high in small language programs, and the availability of these materials may facilitate the integration of new faculty members. Thus, relatively minor steps (guidance for materials and effective organization) can make a world of difference for faculty members in small language programs in their efforts to meet departmental, divisional, and campus requirements.

\section{Colleen Ryan, Indiana University, Bloomington}

Indiana University has many times been rated by The Best Colleges as one of the ten most "innovative colleges for FL [foreign language] study" for several reasons, including its impressive variety of rare language offerings, ranging from Afrikaans to Zulu; its on-campus immersion opportunities, particularly the summer language programs ranging from Arabic to Ukrainian; and its long-standing blends of language and cultural learning with dormitory life through the Foster International Learning and Living Center, which focuses on service learning and community development, and the Global Village Living-Learning Center, which focuses on multicultural and international affairs and foreign language proficiency. 
Managing Small

Language Programs in

Changing Times

Marc L. Greenberg
As in most institutions, there are numerous campus entities and levels of administration upholding accountability measures for foreign language teaching and learning. While Institutional Research and Reporting Services and Institutional Research Council operate at the highest level for overarching institutional purposes of, say, accreditation, foreign language departments must also report to and through the university's general education assessment initiatives and the more recent department and program assessment initiatives. The most regular and palpable contact that most students and faculty members are likely to have with accountability measures, however, regards the quality of teaching and learning at the course level, identifiable through clearly stated learning objectives and a variety of appropriate, aligned assessments. At the same time, it is possible for this daily practice level of accountability for foreign language study to be subsumed or even effaced by the evaluation procedures implemented at the end of each term (university teacher course evaluations) but rarely to garner input from the majority of students or be discussed or analyzed in any forum afterward.

Formal documentation on evaluation policies and procedures directly affecting foreign language programs is hard to find. The Center for Evaluation and Educational Policy carries fees and does much of its work for external clients, and the Office of Overseas Studies has formal evaluation procedures for foreign language teaching and learning. But beyond these units, the primary vehicles for evaluation (and, therefore, holistic reflections and revisions) seem to be at the level of external program review procedures, internal program assessment, and teacher course evaluations, which were recently stipulated in online format for all courses and all instructors regardless of rank and experience.

Of course, the formality and regularity of accountability and evaluation practices may vary from department to department or language to language, regardless of size. Nonetheless, as has been confirmed by John Norris and Nicole Mills, most successful programs, large and small, have taken "ownership" over the processes of evaluation by adopting an "evaluation culture." This culture

comes about through the development of language educators' capacities (knowledge and skills) to engage in evaluation methods, through the sustained completion of evaluation cycles and ensuing programmatic improvements, and through the creation of an ethos of collaborative inquiry, open communication, and willingness to change on the basis of empirical evidence.

Not only does such an evaluation culture have, as Norris and Mills suggest, the potential to resist "uninformed, pernicious, or ineffectual evaluation mandates" (6); it also has the potential to foster top-quality intra- and interdepartmental collaborations, enhancing the overall state of health of our programs and their relevance to every other field of study, not only to the liberal arts.

Therefore, a primary recommendation one could make to chairs and directors who aim to revitalize their departments or reclaim their stakes in the landscape of foreign language and liberal arts education is to reframe or redefine what small program means in their local context: small might indicate enrollment figures as much as enrollment trends, visibility, or conceptual relevance in the larger panorama of degree programs campus-wide. In the process, it seems imperative to ask, What can 
Managing Small

Language Programs in

Changing Times

Marc L. Greenberg we learn from small (rare, unique, innovative) programs that is potentially applicable and beneficial to small (smaller because shrinking or smaller because, even if holding size, becoming institutionally marginal) programs? Another way to cast this question might be, What do small (size or other) but successful programs have that large but stagnant, shrinking, or institutionally insignificant ones do not?

In considering strategies to help departments and chairs manage and maintain (if not grow) their programs, we might suggest three proactive and integrated ways of employing the term small to the benefit of the program, whether it be large or small, quantitatively speaking. The overarching rationale here is that large programs for commonly taught languages (Spanish, French) or less commonly taught languages (Italian) that have not had to struggle to grow or maintain their program size and quality over the decades would do well in the current climate to adopt the perspectives and approaches of small programs - new or old — that have had to both assert and demonstrate their value and crucial place in the broader scheme of foreign language learning. Hence, we can conceive of small-program mentalities in terms of unique, rare, or innovative content material; learning objectives; and course offerings. The goal is to be attractive through difference; it is somewhat of a niche marketing strategy. Or we can conceive of small-program mentalities as an opportunity for updating and revising in terms of program identity, mission, and curriculum mapping. This approach is more of a survival strategy. Finally, we can adopt the small-program mentalities to our advantage if we consider ourselves an essential part of a larger whole - that larger whole being, of course, the array of humanities disciplines, globally oriented learning objectives, and the benchmarks of a twenty-firstcentury liberal education. One might call this the "we're indispensable" strategy.

Whether we favor the first, second, third, or another variation of these revitalizing strategies, it seems essential that department chairs of small (literally or conceptually) programs have a clear and vibrant vision that includes but also extends beyond often lofty mission statements to become tangibly traceable in the daily work of teaching and learning, curriculum planning, and degree programs evaluations. Equally important are the departments' visibility and legibility for the broadest of possible constituencies, but particularly for prospective and current students. A Web site attuned to the visual orientation and navigation practices of students will allow them to enter the departmental culture and feel comfortable with that first encounter or space with greater ease. Visual testimonies of recent alumni with interesting jobs and returnees from study-abroad experiences provide some of the most stimulating and convincing information for students and parents alike. The Web site is another key opportunity to show the indispensable factor: the design, content, and digital student testimonies can promote small programs as essential and irreplaceable parts of the institution's academic enterprise. Impeccably conceived, these sites can synthesize and articulate the vital connection and vibrant role that even the smallest language program can play across disciplines and degree programs for today's students.

\section{Marc L. Greenberg, University of Kansas}

The experience at the University of Kansas is similar in type to Colleen Ryan's at Indiana University, though we have had somewhat different circumstances and have 
Managing Small

Language Programs in

Changing Times

Marc L. Greenberg accordingly devised our own strategy. Like Indiana, Kansas offers a wide range of languages - at last count, some forty of them-and has traditional Europeanlanguage departments as well as East Asian and also Arabic and African languages situated in our Department of African and African-American Studies. The growth of our less commonly taught languages is a function of having built up area studies centers throughout the duration of the Cold War, with the help of consistent and robust Title VI funding. As we saw these federal resources shrinking after 2008, we began, under the leadership of a visionary dean, Danny Anderson (a professor of Latin American literature), to develop a faculty-driven plan to create the School of Languages, Literatures and Cultures, which launched in 2015. The school, which preserves the inherited foreign language departmental structures within it, deploys a number of strategies that are intended to make language programs sustainable and less dependent on a single source of external revenue. The big conceptual idea behind the school is to change the perception of languages as a mere requirement, and one that is encumbered by deeply ingrained mythologies ("too difficult to learn," "everyone speaks English," etc.), to a high-value proposition that belongs at the center of a twenty-first-century education. There are much data and many narratives to draw on to support this message, so we made it a priority to hire a communications director as one of the first steps in structuring the school's office staff. This position, which is occupied by a talented $\mathrm{KU}$ alumnus with a background in marketing and a polyglot's repertoire (native Czech and German, as well as Italian), has helped us to meet other goals, such as strengthening our ties to regional K-12 schools and community colleges as well as to employers in the Kansas City metro area (and well beyond) looking for globally competent and multilingual employees. We have also focused on professional development for language teachers of less commonly taught languages not aligned with the inherited language departments (e.g., Hindi, Kichwa, Persian, Turkish, and Uyghur), which had fallen between the cracks. These lecturers are part of a community of practice that we have organized as the Critical Languages Consortium, led by a specialist in the teaching of less commonly taught languages. The consortium provides better integration of the lecturers in the network of teaching specialists in the language departments, funding for travel to professional meetings, and opportunities to share best practices and attend to matters such as peer evaluation, student outcomes assessment, and the hiring and socialization of Fulbright foreign language teaching assistants.

A remarkable transformation has happened as a product of the school project: from the moment faculty members from various foreign language and other departments started engaging in planning discussions, we opened up lines of communication among faculty members that had previously been isolated in narrow departmental circulation patterns. This led to a great deal of creative thinking about what we could accomplish across departments, from more traditional pursuits, such as creating a cross-cutting second-language studies curriculum, a focus on medieval studies and comparative literature, to a cutting-edge program in global medical humanities that takes advantage of a unique WHO-affiliated project, the Community Tool Box, that gives language students a way to participate through experiential learning to contribute to public health practices in widely differing cultural contexts. 
Managing Small

Language Programs in

Changing Times

Marc L. Greenberg
The global medical humanities curriculum, which is still in development, brings together anthropologists, sociologists, public health specialists, psychologists, digital humanities practitioners, and literary scholars (think medical ethics in Tolstoy), as well as others in its teaching cohort. We think this program will not only be exciting for students but also open up opportunities for hands-on learning that will translate into valuable workforce-ready skills and modes of thinking.

Uniting small departments into a larger whole has also allowed us to pursue fundraising in a systematic way. We have been delighted by the consistently enthusiastic support of our alumni, even going back many decades, who have encouraged us through words and deeds. Our school's growing advisory board has helped us continue to connect to our alumni network, brought alumni and new community friends to campus, and connected us to relevant programs, such as the Global Language Project in New York City, which provides language instruction to underserved communities as a means of economic empowerment.

Although we are still in the early days of the school, we have begun a tradition that we hope will be sustained well into the future: on 1 September (if it falls on a weekday), we hold our school convocation, to which we bring alumni speakers to tell their stories about the importance of foreign language and global competence for a modern education. The inspirational stories and the resonance on campus and well beyond have exceeded all our expectations. Have all these efforts translated into higher enrollments? They certainly have. Whether the upticks have been enough to outpace relentless budget cutbacks, however, remains to be seen.

\section{Works Cited}

Goldberg, David, et al. Enrollments in Languages Other Than English in United States Institutions of Higher Education, Fall 2013. Modern Language Association, Feb. 2015, www.mla.org/Resources/Research/Surveys -Reports-and-Other-Documents/Teaching-Enrollments-and-Programs/Enrollments-in-Languages -Other-Than-English-in-United-States-Institutions-of-Higher-Education/Enrollments-in-Languages -Other-Than-English-in-United-States-Institutions-of-Higher-Education-Fall-2013.

MLA Ad Hoc Committee on Foreign Languages. "Foreign Languages and Higher Education: New Structures for a Changed World.” Modern Language Association, 2007, www.mla.org/flreport.

Norris, John, and Nicole Mills. "Introduction: Innovation and Accountability in Foreign Language Program Evaluation." AAUSC 2014 Volume - Issues in Language Program Direction: Innovation and Accountability in Language Program Evaluation. Edited by Norris and Mills, Cengage, 2014, pp. 1-14.

“Top Ten Most Innovative Colleges for Foreign Language Learning for 2018." The Best Colleges, 2018, www.thebestcolleges.org/rankings/10-most-innovative-colleges-for-foreign-language-study/. 